\title{
Epidermal Growth Factor Regulates the In Vitro Sensitivity of Human Ovarian Carcinoma Cells to Cisplatin
}

\author{
Randolph D. Christen, * Doreen K. Hom, * Donald C. Porter," Paul A. Andrews," \\ Carol L. MacLeod," Larsolof Hafstrom," and Stephen B. Howell* \\ *Department of Medicine and the Cancer Center, University of California, San Diego, La Jolla, California 92093; \\ and ${ }^{\ddagger}$ Department of Surgery, Sahlgrenska Hospital, University of Goteborg, S-41345 Goteborg, Sweden
}

\begin{abstract}
Cisplatin (DDP) is the most effective drug for the treatment of human ovarian cancer, but the mechanisms that determine sensitivity to the cytotoxic action of DDP are not well understood. Treatment of two human ovarian carcinoma cell lines with epidermal growth factor (EGF) simultaneously increased sensitivity to DDP and caused a persistent change in morphology in the absence of any mitogenic effect. Sensitization to DDP was shown to be dependent on both EGF concentration and EGF receptor number in $\mathbf{C 1 2 7}$ mouse fibroblasts expressing the human EGF receptor after transfection with a pBPV plasmid construct containing the human EGF receptor gene under control of the transferrin receptor 3 '-inducible regulator. Sensitization of human ovarian carcinoma cells to DDP was not blocked by inhibition of protein synthesis. EGF did not enhance sensitivity to DDP or alter morphology in DDP-resistant human ovarian carcinoma cells despite the presence of functional EGF receptors on these cells. These results showed that elements of the signal transduction pathway activated by EGF determined cellular sensitivity to DDP, and that a DDPresistant phenotype is associated with a defect in this signal transduction pathway. (J. Clin. Invest. 1990. 86:1632-1640.) Key words: drug resistance $\bullet$ epidermal growth factor receptor • transferrin receptor $3^{\prime}$-inducible regulator $-\mathrm{pBPV}$ plasmid construct • C127 mouse fibroblasts
\end{abstract}

\section{Introduction}

Platinum complexes, particularly cisplatin (DDP), ${ }^{1}$ are drugs of major importance in cancer therapy. However, both intrinsic and acquired resistance to DDP occurs frequently. Cells selected for resistance to many antimetabolites (1), and to drugs participating in the multiple drug resistance phenotype (2), often exhibit very high levels of resistance. In contrast,

Portions of this work were presented at the 81 st Annual Meeting of the American Association for Cancer Research, Washington, DC, May 1990, and have been published in abstract form (1990. Proc. Am. Assoc. Cancer Res. 31:53a).

Address correspondence to Randolph D. Christen, M.D., Department of Medicine, 0812; University of California San Diego, La Jolla, CA 92093.

Received for publication 28 November 1989 and in revised form 8 June 1990.

1. Abbreviations used in this paper: DDP, cisplatin; EGF, epidermal growth factor.

J. Clin. Invest.

(C) The American Society for Clinical Investigation, Inc.

0021-9738/90/11/1632/09 \$2.00

Volume 86, November 1990, 1632-1640 both in vitro and in vivo selection with DDP at clinically relevant intensities usually results in low-level resistant cells which are only two- to fourfold resistant to this drug (3-6). Attempts to enhance the sensitivity to DDP have focused on strategies such as reduction of glutathione (7-10) and inhibition of DNA repair $(11,12)$.

Binding of epidermal growth factor (EGF) to its receptor induces tyrosine phosphorylation of various cellular proteins including the EGF receptor itself. It has been exceedingly difficult to identify the key substrates that become phosphorylated besides the receptor itself, so the exact role of tyrosine phosphorylation in signal transduction remains uncertain. EGF receptor activation induces a variety of changes in intracellular physiology including activation of the $\mathrm{Na}^{+} / \mathrm{H}^{+}$transporter (13), increase in calcium influx (14), activation of glycolysis (15), enhanced prostaglandin biosynthesis (16), induction of ornithine decarboxylase and accumulation of putrescine (17), changes in membrane potential (18), inositol phosphate formation $(19,20)$, activation of protein kinase $C$ (21), S 6 ribosome phosphorylation (22), oncogene expression (23-27), stimulation of DNA synthesis (28), and cell proliferation (28).

We report here that activation of the receptor signal transduction pathway of the naturally occurring ligand EGF, can both enhance sensitivity to DDP, and produce morphologic changes consistent with activation of a differentiation program in two human ovarian carcinoma cell lines. While stimulation of DNA synthesis or cell proliferation are not required for EGF-induced sensitization to DDP, which of the many EGFinduced changes in cellular physiology are involved is currently not understood.

\section{Methods}

Cell lines and cell culture. Two well-characterized human ovarian carcinoma cell lines, designated 2008 (29) and COLO 316 (30), and a DDP-resistant variant $2008 / \mathrm{Cl}^{*}$, derived from the parent 2008 cell line (31) were used in these studies. The 10-fold DDP-resistant cell line $2008 / \mathrm{Cl}^{*}$ was generated by 13 monthly selections with $1 \mu \mathrm{M}$ DDP (31), followed by chronic exposure to stepwise increasing concentrations of DDP from 0.25 to $5.0 \mu \mathrm{M} .2008$ cells and COLO 316 cells were maintained in exponential growth in RPMI medium 1640 supplemented with $5 \%$ heat-inactivated bovine calf serum, $2 \mathrm{mM}$ freshly added glutamine, and $1 \%$ penicillin-streptomycin solution (Irvine Scientific, Santa Ana, CA). The parent and transfected $\mathrm{C} 127$ mouse fibroblasts were maintained in exponential growth in DME containing $4.5 \mathrm{~g}$ glucose per liter, $10 \%$ heat-inactivated FCS, and $2 \mathrm{mM}$ glutamine.

Clonogenic assay. Clonogenic assays were performed by seeding 300 cells per $60 \mathrm{~mm}$ tissue culture plastic dish (Corning Glass Works, Corning, NY). The cells were allowed to attach overnight. On the next day, cells treated with EGF (murine EGF, Sigma Chemical Co., St. Louis, MO) were exposed to $10 \mathrm{nM}$ EGF for $1 \mathrm{~h}$ and then to both EGF 
and DDP during the second hour. The media was changed, and the colonies that formed were counted after $10 \mathrm{~d}$ of incubation in humidified $5 \% \mathrm{CO}_{2}$ at $37^{\circ} \mathrm{C}$. Cell clusters containing $>50$ cells were scored as a colony.

Growth assay. COLO 316, 2008, and 2008/C13* were seeded in 24-well plates (Corning Glass Works) at a density of 50,000 cells per well. Cells were treated with $10 \mathrm{nM}$ EGF either for $2 \mathrm{~h}$ or continuously. The cell numbers were determined after trypsinization using a hemocytometer.

Scatchard analysis of EGF binding. EGF binding assays were performed with some modifications as described by Kawamoto et al. (32). 3-( ${ }^{125}$ I) Iodotyrosyl EGF (human recombinant), specific activity 9,000 $\mathrm{Ci} / \mathrm{mmol}$, was purchased from Amersham Corp. (Arlington Heights, IL). Subconfluent 2008, 2008/C13*, and COLO 316 cells grown in 150 $\times 25 \mathrm{~mm}$ tissue culture plates were fixed with $0.2 \%$ paraformaldehyde for $10 \mathrm{~min}$ at room temperature to prevent receptor internalization during incubation with EGF (33). Cells were scraped off with a rubber policeman and washed three times with $0.2 \%$ BSA (Sigma Chemical Co.) in PBS and resuspended in the same buffer at a cell density of 5 $\times 10^{6}$ per $\mathrm{ml}$. For binding assays, $200 \mu \mathrm{l}$ of cell suspension $\left(\sim 1 \times 10^{6}\right.$ cells) were incubated with $1 \mu \mathrm{Ci}^{125}$ I EGF dissolved in $200 \mu \mathrm{l} 0.2 \%$ BSA in PBS. After a 2-h incubation, cells were quantitatively collected on low protein binding hydrophilic Durapore membranes (pore size 0.22 $\mu \mathrm{m}$, purchased from Millipore Corp., Bedford, MA) by suction. To prevent nonspecific binding of EGF, the filters were pre-wet with $0.25 \%$ gelatin (J. T. Baker Chemical Co., Phillipsburg, NJ) and $1 \%$ BSA in PBS. After cell collection, the filters were washed five times with $0.2 \%$ BSA in PBS. The filters were dried and radioactivity was measured in a gamma counter. Calculation of receptor number and $K_{d}$ was performed as described by Scatchard (34).

Assessment of the EGF receptor number with monoclonal antibodies (MAbs) directed toward the human EGF receptor. MAb 455 (35-37) was used to quantitate the EGF-induced down-regulation of the EGF receptor number in 2008 and $2008 / \mathrm{Cl}^{*}$ cells. MAb 455 is directed toward the carbohydrate moiety of the human EGF receptor, and does not competitively inhibit the binding of EGF to its receptor (35-37). After harvesting the cells by trypsinization, all the following steps were performed on ice. The cells were washed twice with wash buffer $(0.5 \mathrm{mM}$ EDTA, $2 \mathrm{mM}$ sodium azide, and $1 \mathrm{mg} / \mathrm{ml} \mathrm{BSA}$ in PBS). Then the cells were incubated with $100 \mathrm{nM} 455 \mathrm{MAb}$ in wash buffer for $45 \mathrm{~min}$. After washing the cells were stained with a fluorescent goat anti-mouse IgG/IgM antibody from Caltag Laboratories (San Francisco, CA) for $45 \mathrm{~min}$ in the dark. The cells were analyzed on a CytoFluorograf (Ortho Diagnostics Systems, Raritan, NJ) with excitation and emission settings of 488 and $530 \mathrm{~nm}$, respectively. Similarly, in transfected $\mathrm{C} 127$ cells, changes in expression of the human EGF receptor number were quantitated with MAb 528 (35-37) as primary antibody. This latter antibody is specific for the protein core of the human EGF receptor (35-37). To determine the change in EGF receptor number within a given cell line, the change in the peak of mean intensity of fluorescence was used.

Transfection of C127 mouse fibroblasts. C127 mouse fibroblasts were stably transfected with a pBPV plasmid construct containing the human EGF receptor gene under the control of the transferrin receptor 3'-inducible regulator (Porter, D. C., manuscript in preparation). In brief, the plasmid vectors pSV2B and pBPV were obtained from Dr. J. Rose (Yale University, New Haven, CT). Plasmid preparation and all molecular manipulations were carried out using standard molecular biological techniques (38). DNA inserts were isolated from low-melt agarose gels and fragments purified by absorption and elution from NACS-52 columns (Bethesda Research Laboratories, Gaithersburg, MD). The BPV vector expressing the transferrin receptor was constructed as follows. A full-length transferrin receptor cDNA was isolated as a 5-kb BamH1 fragment from pCDTR1 (39). The fragment was cloned into the HindIII/BglII sites of pSV2B. pSV2B is a derivative of pSV2 in which the PvuII site upstream of the SV40 promoter has been converted into a Bam $\mathrm{H} 1$ site. A BamH 1 fragment containing the SV40 promoter, transferrin receptor insert, SV40 polyadenylation sequences, and small $t$ antigen splice site was then removed and cloned into the BamH1 site of the transforming vector pBPV. The pBPV/ transferrin receptor vector containing the coding and noncoding sequence of the transferrin receptor was used to construct a hybrid gene composed of the coding sequence of the EGF receptor gene in place of the transferrin receptor coding sequence. In this plasmid, the transferrin receptor noncoding sequence was left intact and was placed $3^{\prime}$ to the EGF receptor gene. The $\mathrm{pBPV} /$ transferrin receptor plasmid was cut with the restriction enzymes $E c o$ RV and BglII which removed the entire transferrin receptor coding sequence while leaving the SV40 promoter and noncoding transferrin receptor sequence intact. The $B g / I I$ sticky end was filled in with $\mathrm{T}, \mathrm{A}$, and $\mathrm{G}$ nucleotide triphosphates and DNA polymerase I (Klenow fragment). The final unpaired nucleotide was removed with mung bean nuclease. This created an $E c o R V$ restriction site between the SV40 promoter and the transferrin receptor noncoding sequence upon self ligation. This plasmid was designated $\mathrm{pBPV} /$ transferrin receptor noncoding sequence. The entire EGF receptor cDNA coding sequence was removed from the vector pX-gen (kindly provided by Dr. Gordon Gill, University of California San Diego, La Jolla, CA) with restriction enzymes $X b a I$ and HindIII. The 4.0-kb fragment containing the EGF receptor coding sequence was electroeluted from high-melt agarose, made blunt with mung bean nuclease, and ligated into the $E c o \mathrm{RV}$ site of the plasmid pBPV/transferrin receptor noncoding sequence just described. Finally, the plasmid pBPV/EGF receptor coding sequence/transferrin receptor noncoding sequence was successfully transfected into mouse $\mathrm{C} 127$ fibroblasts using calcium phosphate transfection method (38).

Expression of the transferrin receptor gene is normally under the control of the transferrin receptor 3 '-inducible regulator, and is regulated by iron (40). Incubation with the iron chelator deferoxamine induces expression of the transferrin receptor gene (41). To induce the EGF receptor number expressed on transfected $\mathrm{C} 127$ cells, the cells were treated with $10 \mu \mathrm{M}$ deferoxamine mesylate (Desferal mesylate, Ciba-Geigy, Basel, Switzerland) and $25 \mu \mathrm{g} / \mathrm{ml}$ transferrin (human transferrin iron saturated, ICN Immuno Biologicals, Lisle, IL) for $60 \mathrm{~h}$. The total number of EGF receptors, including murine and human, was determined by Scatchard analysis in parent and transfected $\mathrm{C} 127$ cells. In addition to Scatchard analysis, expression of human EGF receptors in transfected $\mathrm{C} 127$ cells was quantitated by flowcytometry using as primary antibody MAb 528 specific for the human EGF receptor (35-37).

Tetrazolium/formazan growth rate assay. Because $\mathrm{C} 127$ mouse fibroblasts do not form uniform colonies on plastic dishes, the sensitivity of control and deferoxamine-induced transfected $\mathrm{C} 127$ cells to DDP was compared by using a growth rate assay in which the cell number was quantified by tetrazolium dye reduction (42). 1,500 cells were seeded in $180 \mu \mathrm{l}$ of DME containing $4.5 \mathrm{~g}$ glucose per liter, $10 \%$ heat-inactivated FCS, $25 \mu \mathrm{g} / \mathrm{ml}$ human transferrin (holoform), and 10 nM EGF. DDP at different concentrations was added in $20 \mu$ l of saline to triplicate culture wells, and cultures were incubated for $6 \mathrm{~d}$ in humidified $5 \% \mathrm{CO}_{2}$ in air at $37^{\circ} \mathrm{C}$. MTT (3-[4,5-dimethylthiazol-2-yl]2,5-diphenyl tetrazolium bromide, Sigma Chemical Co.) was prepared at $1 \mathrm{mg} / \mathrm{ml}$ in DME medium and on day $7,50 \mu \mathrm{l}$ were added to the microculture wells. After a 4-h incubation at $37^{\circ} \mathrm{C}$, all the media was removed from each well, and $150 \mu \mathrm{l}$ of $100 \%$ DMSO was added to solubilize the MTT-formazan product. After thorough mixing absorbance at $540 \mathrm{~nm}$ was measured with a $V_{\max }$ Kinetic Microplate Reader (Molecular Devices, Inc., Palo Alto, CA).

Inhibition of protein synthesis. Cycloheximide was used to inhibit protein synthesis (43). In preliminary experiments we have shown that incubation of 2008 cells with $5 \mu \mathrm{g} / \mathrm{ml}$ cycloheximide reduced protein synthesis by $85 \%$ after $10 \mathrm{~min}$, and by $90 \%$ after $2 \mathrm{~h}$, respectively. To assess whether EGF-induced enhanced sensitivity to DDP was dependent on new protein synthesis, 2008 cells were preincubated with 5 $\mu \mathrm{g} / \mathrm{ml}$ cycloheximide for $10 \mathrm{~min}$, followed by exposure to cycloheximide and EGF for $1 \mathrm{~h}$, and cycloheximide, EGF and DDP for another hour. Immediately after drug exposure, cells were exposed to $25 \mu \mathrm{Ci}$ / $\mathrm{ml}\left[{ }^{35} \mathrm{~S}\right]$ methionine (Amersham Corp., Arlington Heights, IL) for $3 \mathrm{~h}$. 

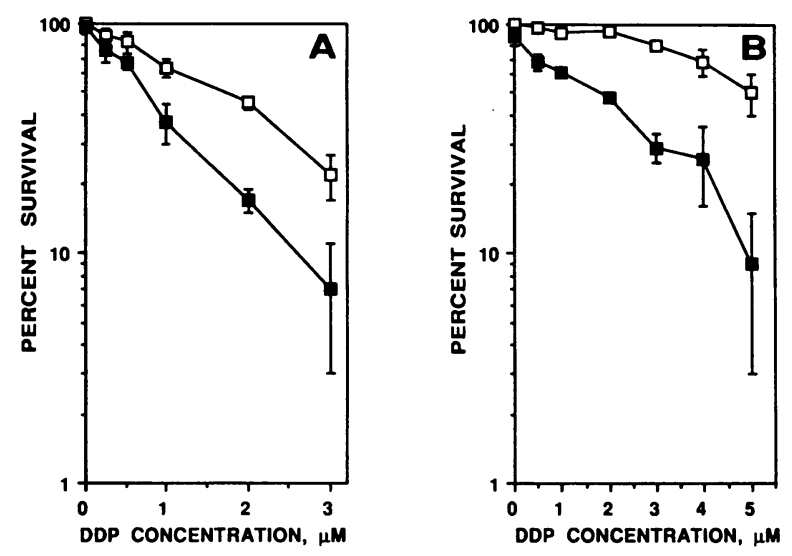

The incorporation of $\left[{ }^{35} \mathrm{~S}\right]$ methionine into protein was determined by precipitation of whole cell lysate proteins in 10\% TCA (in the presence of $0.5 \%$ casamino acids) on glass-fiber filters; the precipitated material was counted in a $\beta$-scintillation counter.

\section{Results}

Fig. 1 shows the effect of EGF on the sensitivity to DDP in COLO 316, 2008, and 2008/C13* cells. Cells were exposed to $10 \mathrm{nM}$ EGF for $1 \mathrm{~h}$, and then to both EGF and DDP during a second hour. EGF increased the sensitivity of 2008 and COLO 316 cells by $3.1 \pm 0.9$-fold, and $2.4 \pm 0.1$-fold, respectively, as quantified by the ratio of the $\mathrm{IC}_{50}$ values. The EGF-induced decrease of the $\mathrm{IC}_{50}$ values were significant in both the 2008 and the COLO 316 cell lines $(P<0.004$ and $P<0.001$, respectively, by two-sided $t$ test for the comparison with untreated cells). EGF did not alter the sensitivity of $2008 / \mathrm{Cl}^{*}$ cells to DDP.

The observed modulation of sensitivity to DDP by EGF was not due to an EGF-induced change in growth rate. The effect of both a 2-h exposure and continuous exposure to 10 nM EGF on growth rate was assayed using the same culture conditions under which EGF enhanced the sensitivity to DDP. During the first $5 \mathrm{~d}$ after cell seeding, cell growth was exponential. The doubling times of the 2008, 2008/C13*, and COLO 316 cells were $27.9,28.2$, and $29.2 \mathrm{~h}$, respectively. Neither a 2-h nor a continuous exposure to $10 \mathrm{nM}$ EGF had any demonstrable impact on the growth rate of these cell lines.

The effect of EGF on the sensitivity of 2008 cells to DDP was concentration dependent (Fig. 2). Control cells were exposed to increasing concentrations of EGF alone. EGF- and DDP-treated cells were exposed to EGF at increasing concentrations combined with DDP at a fixed concentration of $2 \mu \mathrm{M}$. First, the cells were exposed to EGF for $1 \mathrm{~h}$, and then to both EGF and DDP concurrently during the second hour. A 2-h exposure to EGF ( $1 \mathrm{~h}$ before and $1 \mathrm{~h}$ concurrent with DDP) enhanced sensitivity to DDP at EGF concentrations as low as $0.4 \mathrm{nM}$, and the effect was maximal at concentrations of $\sim 10$ $\mathrm{nM}$ (approximately four times the $K_{\mathrm{d}}$ of the EGF receptor). As expected, a further increase in the EGF concentration up to $100 \mathrm{nM}$ produced no additional change in sensitivity to DDP. The data presented in Fig. 2 is consistent with saturation of EGF binding at EGF concentrations over $10 \mathrm{nM}$, or with the presence of two distinct cell populations of which one is totally unresponsive to EGF. The latter possibility has not been formally excluded.

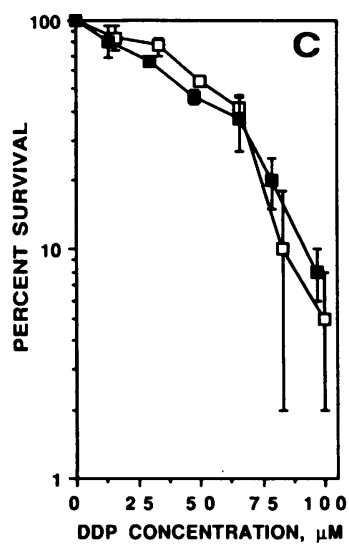

Figure 1. Effect of EGF on the sensitivity to DDP. COLO $316(A), 2008$ cells $(B), 2008 / C 13^{*}$ cells $(C)$. Clonogenic assays were performed by seeding 300 cells per $60-\mathrm{mm}$ plastic dish. Cells treated with EGF were exposed to 10 $\mathrm{nM}$ EGF for $1 \mathrm{~h}$ and then to both EGF and DDP during the second hour. The colonies that formed were counted after $10 \mathrm{~d}$. Cell clusters containing $>50$ cells were scored as a colony. Each data point represents the mean $( \pm \mathrm{SD})$ of three separate experiments each performed with triplicate cultures (Open squares) DDP alone; (solid squares) DDP and EGF.

The time course of the EGF effect on the sensitivity of 2008 cells was determined by exposing cells to $10 \mathrm{nM}$ EGF for $1 \mathrm{~h}$, and then to DDP at a fixed concentration of $2 \mu \mathrm{M}$ either concurrently or with an increasing delay between the $1 \mathrm{~h}$ EGF pretreatment and $1 \mathrm{~h}$ DDP exposure (Fig. 3). After the 1-h exposure to EGF the media was changed, and DDP at a fixed concentration of $2 \mu \mathrm{M}$ was added for $1 \mathrm{~h}$ at the following time points: $0,1,2,3,4,5$, and $24 \mathrm{~h}$ after the start of the 1-h exposure to EGF. Thus, there was an increasing time period in which cells were incubated without EGF before DDP was added. When given concurrently with DDP, EGF significantly increased sensitivity to DDP as compared with control cells treated with DDP alone. Sensitivity to DDP increased even further when cells were exposed to EGF for $1 \mathrm{~h}$ before treatment with DDP. The EGF-mediated increase in sensitivity to DDP persisted for at least $5 \mathrm{~h}$, but had largely disappeared by 24 h (Fig. 3).

In addition to enhancing sensitivity to DDP, and despite the lack of effect on growth, a 2-h exposure to EGF had marked effects on the morphology of the 2008 and COLO 316

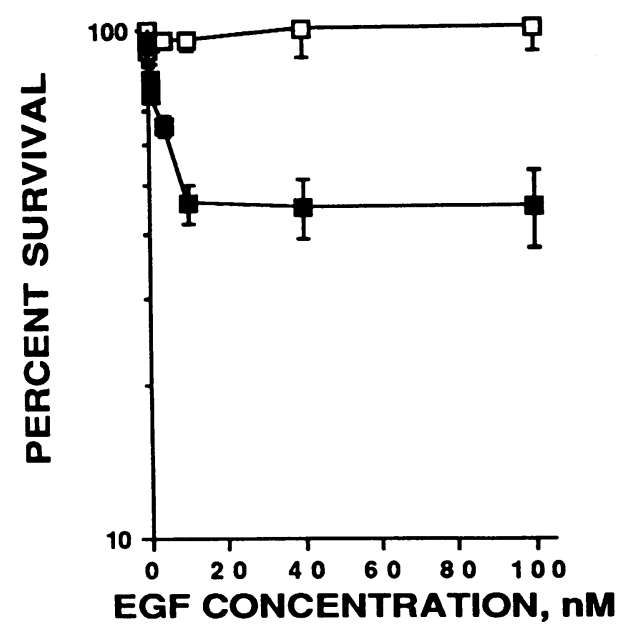

Figure 2. EGF concentration-dependence of DDP sensitization in 2008 cells. (Open squares) control cells, exposed to EGF alone for 2 $\mathrm{h}$ at increasing concentrations. (Solid squares) Cells exposed to EGF and DDP. Cells were exposed first to EGF for $1 \mathrm{~h}$, and then to both varying concentrations of EGF and $2 \mu \mathrm{M}$ DDP concurrently during the second hour. Colonies were counted after $10 \mathrm{~d}$ of incubation. Each data point represents the mean $( \pm S D)$ of three different experiments. 


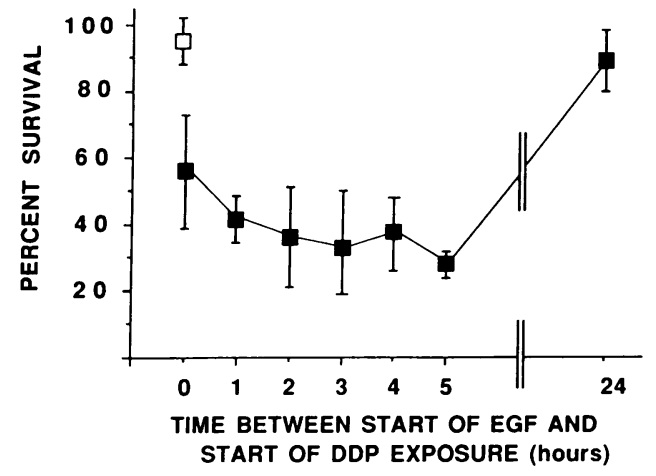

Figure 3. Time course of EGF-induced sensitization to DDP in 2008 cells. Cells were exposed to $10 \mathrm{nM}$ EGF for $1 \mathrm{~h}$. DDP at a fixed concentration of $2 \mu \mathrm{M}$ was added to the media either concurrently with EGF or with increasing delay after the start of the $1 \mathrm{~h}$ EGF exposure. The abscissa represents the number of hours between the start of the 1-h EGF exposure and the start of the 1-h DDP exposure. Colonies were counted after $10 \mathrm{~d}$ of incubation. Each data point represents the mean $( \pm \mathrm{SD})$ of three different experiments. (Open square) DDP alone; (solid squares) EGF and DDP.

cells (Fig. 4). At the macroscopic level, colonies formed by the 2008 and COLO 316 cells $10 \mathrm{~d}$ after a 2-h exposure to $10 \mathrm{nM}$ EGF were much larger and stained less intensely with Giemsa. At the microscopic level, colonies formed from untreated cells consisted of tightly packed cells, whereas colonies arising after EGF treatment consisted of widely scattered cells of which 10-20\% had formed prominent dendritic processes. The lower cell number displayed in the photographs taken from EGFtreated cells is due to the marked scattering of the cells, and does not reflect an EGF-induced change in growth rate. It was of particular interest that $2008 / \mathrm{C}^{*} 3^{*}$ cells, in which EGF failed to alter DDP responsiveness, showed no morphological response to a 2 h EGF exposure.

The receptor number per cell and the $K_{d}$ of the EGF receptor were determined by Scatchard analysis (18) in the DDPsensitive 2008 and COLO 316 cells, and the DDP-resistant $2008 / \mathrm{Cl}^{*}$ subline. The data is summarized in Table 1 . The Scatchard plots were monophasic in all cell lines examined, suggesting the presence of a single class of EGF receptors with the same $K_{\mathrm{d}}$. The $K_{\mathrm{d}}$ for $2008,2008 / \mathrm{C} 13^{*}$, and COLO 316 cells were of the same order of magnitude. 2008 cells expressed approximately threefold more EGF receptors as compared with $2008 / C 13^{*}$ cells. Even though the EGF receptor number was similar in the COLO 316 and the $2008 / \mathrm{C13}$ * cells, the former were responsive to EGF and the latter nonresponsive to EGF in terms of sensitization to DDP and changes in morphology. Thus, no apparent correlation between EGF binding and its ability to sensitize cells to DDP and to induce morphological changes was found in different human ovarian carcinoma cell lines, suggesting that factors other than the EGF receptor number are determinants of the biological response to EGF in different cell lines.

The functionality of the EGF receptors was assayed in 2008 cells and $2008 / \mathrm{C}^{*} 3^{*}$ cells by demonstrating down-regulation of the receptor number upon binding to EGF. EGF receptors were quantitated by flowcytometry, using as primary antibody MAb 455 directed against the carbohydrate moiety of the human EGF receptor (35-37). A 1-h incubation of 2008 and $2008 / \mathrm{C} 13^{*}$ cells with $100 \mathrm{nM}$ EGF at $37^{\circ} \mathrm{C}$ caused down- regulation of $60-70 \%$ of the EGF receptors on both DDP-sensitive and resistant cells (data not shown). Control cells were treated with $100 \mathrm{nM}$ EGF for $1 \mathrm{~h}$ on ice, a condition known to prevent receptor down-regulation $(37,44)$. Using EGF receptor mutants lacking intrinsic protein tyrosine kinase activity, it has been convincingly shown that tyrosine kinase activity is essential for signal transduction and for receptor down-regulation upon binding to EGF $(45,46)$. Therefore, it can be concluded that both the 2008 and $2008 / \mathrm{C13}^{*}$ cells have functional EGF receptors, which are capable of receptor autophosphorylation upon EGF binding.

To demonstrate that the modulating effect of EGF on DDP sensitivity was transduced by the EGF receptor, we investigated the effect of EGF on the sensitivity to DDP in C127 mouse fibroblasts stably transfected with a plasmid construct containing the human EGF receptor gene under the control of the transferrin receptor 3 '-inducible regulator. The total number of EGF receptors including murine and human receptors was determined by Scatchard analysis in parent and transfected $\mathrm{C} 127$ cells. Parent $\mathrm{C} 127$ cells expressed $\sim 3 \times 10^{3}$ receptors per cell (data not shown). Transfected C127 cells grown in media supplemented with FCS expressed $1.8 \times 10^{5}$ receptors per cell (including murine and human receptors, data not shown). After a 60-h incubation with $10 \mu \mathrm{M}$ deferoxamine mesylate and $25 \mu \mathrm{g} / \mathrm{ml}$ transferrin, transfected C127 cells expressed $4.5 \times 10^{5}$ receptors per cell (including murine and human receptors, data not shown). In addition to Scatchard analysis, expression of human EGF receptors in transfected $\mathrm{C} 127$ cells was quantitated by flowcytometry, using as primary antibody MAb 528, specific for the protein core of the human EGF receptor (35-37). With this assay, deferoxamine treatment was shown to induce expression of the human EGF receptor to approximately twofold, as compared with untreated cells (data not shown). The same assay was used to demonstrate EGF-induced down-regulation of the human EGF receptor in transfected $\mathrm{C} 127$ cells. A 1-h incubation of transfected $\mathrm{C} 127$ cells with $100 \mathrm{nM}$ EGF at $37^{\circ} \mathrm{C}$ caused down-regulation of $50-60 \%$ of the human EGF receptors (data not shown). Control cells were treated with 100 nM EGF for 1 $h$ on ice, a condition known to prevent receptor down-regulation $(37,44)$. By demonstrating receptor down-regulation of the human EGF receptors expressed on transfected $\mathrm{C} 127$ cells upon binding of EGF, it can be inferred that these receptors are functional, i.e., capable of receptor autophosphorylation (vide supra). The sensitivity of control and deferoxamine-induced cells to DDP was compared by using a growth rate assay in which the cell number was quantitated by tetrazolium dye reduction (42). Fig. 5 shows that, in the presence of $10 \mathrm{nM}$ EGF, the deferoxamine-treated cells were approximately twofold more sensitive to DDP than control cells. Deferoxamine at a concentration of $10 \mu \mathrm{M}$ was nontoxic to transfected $\mathrm{C} 127$ mouse fibroblasts, even after prolonged incubation for $2 \mathrm{wk}$, and did not modulate the sensitivity of transfected $\mathrm{C} 127$ cells to DDP in the absence of EGF. Thus, within a given cell line, sensitivity to DDP could be regulated by both EGF concentration and EGF receptor number.

The EGF-induced increase in sensitivity of 2008 cells to DDP was not dependent on new protein synthesis. Under circumstances where DDP and EGF together reduced the survival of 2008 cells to $31 \pm 10 \%$ (SD) of control cells treated with DDP alone, pretreatment with cycloheximide sufficient to inhibit protein synthesis by $85-90 \%$ produced a survival of 

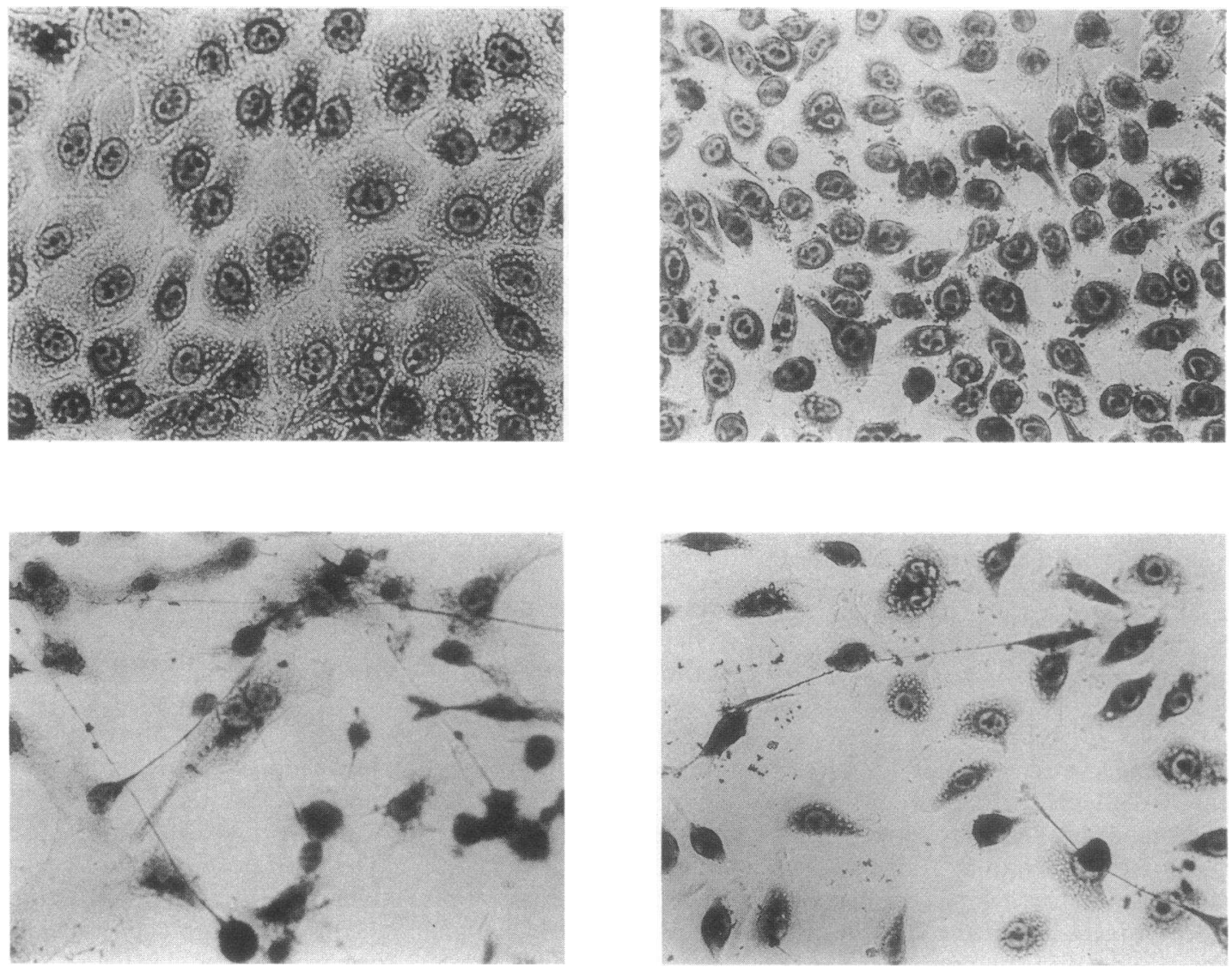

Figure 4. Morphological changes induced by a 2-h exposure to $10 \mathrm{nM}$ EGF in 2008 and COLO 316 cells. Cells were seeded on 60-mm plastic dishes at a density of 300 cells per dish, allowed to attach overnight, and exposed to $10 \mathrm{nM}$ EGF for $2 \mathrm{~h}$ on the following day. Colonies were inspected by light microscopy after $10 \mathrm{~d}$ of incubation. Untreated cells (COLO 316 cells, top left; 2008 cells, top right) showed a dense monolayer of ovoid cells with round nuclei and dense chromatin. The colonies formed by the COLO 316 cells appeared somewhat denser. Lower panels show cells exposed to EGF (COLO 316, bottom left; 2008 cells, bottom right). In both cell lines EGF induced a marked scattering of the cells and the formation of prominent dendritic processes.

$47 \pm 8 \%$ (SD, data not shown). Thus, synthesis of new proteins is not required for EGF-induced sensitization to DDP in 2008 cells.

\section{Discussion}

We observed that EGF enhanced the sensitivity to DDP and induced marked changes in morphology in two human ovarian carcinoma cell lines. Interestingly, EGF failed to induce either effect in DDP-resistant 2008/C13* cells, suggesting a lesion in the EGF receptor signal transduction pathway associated with this DDP-resistant phenotype. The concept that activation of a growth factor signal transduction pathway can modulate the sensitivity of tumor cells to antineoplastic agents is novel, although the precise EGF-induced changes responsible for mediating the enhanced sensitivity to DDP are not yet known.

Our evidence suggests that binding of EGF to its receptor and activation of the EGF receptor tyrosine kinase activity are mandatory for EGF-induced sensitization to DDP. This evidence includes the observation that sensitization to DDP is dependent on both the EGF concentration and the EGF receptor number. Analysis of the EGF concentration dependence in 2008 cells shows that maximal sensitization to DDP occurred at an EGF concentration of $\sim 10 \mathrm{nM}$. This is in agreement with a $K_{\mathrm{d}}$ of $2.4 \mathrm{nM}$ found in this cell line, indicating that maximum sensitization is obtained as binding becomes saturated. Similarly, within a given cell line, the number of EGF receptors expressed per cell was a determinant of the degree of EGF-induced sensitization to DDP, as demonstrated in $\mathrm{C} 127$ mouse fibroblasts transfected with a pBPV plasmid construct containing the human EGF receptor gene under control of the transferrin receptor $3^{\prime}$-inducible regulator. In this model, sensitivity to DDP in the presence of EGF could be increased by approximately twofold by increasing the EGF receptor number by 2.5 -fold. This is strong support for the contention that the effect of EGF on sensitivity to DDP is mediated by binding of EGF to its receptor.

Several lines of evidence indicate that EGF-induced enhancement of sensitivity to DDP is not dependent on new gene transcription. First, time course experiments showed that sensitization to DDP developed relatively rapidly. Almost maximal enhancement of DDP sensitivity was observed after just 1 $h$ exposure to EGF. Second, blockade of new protein synthesis by preincubation with cycloheximide at a concentration sufficient to prevent $85-90 \%$ of protein synthesis did not prevent modulation of DDP sensitivity by EGF. Third, EGF-induced enhancement of sensitivity to DDP was independent of the ability of EGF to act as a mitogen, an effect that is related to 
Table I. Scatchard Analysis of EGF Binding to Human Ovarian Carcinoma Cell Lines

\begin{tabular}{lccc}
\hline Cell line & $\begin{array}{c}\text { Fold increase in } \\
\text { resistance to DDP }\end{array}$ & $\begin{array}{c}\text { No. of EGF } \\
\text { receptors per cell } \\
\left(\times 10^{4}\right)\end{array}$ & $K_{\mathrm{d}}$ \\
\hline & & & $n M$ \\
2008 & 1 & $16.5 \pm 0.7$ & $2.4 \pm 1.3$ \\
$2008 / C 13^{*}$ & 8 & $5.8 \pm 0.9^{*}$ & $4.0 \pm 0.3$ \\
COLO 316 & 1 & $4.3 \pm 0.4$ & $4.0 \pm 1.4$ \\
& & & \\
\hline
\end{tabular}

* $P<0.001$ by two-sided $t$ test for the comparison with 2008 cells. $200 \mu$ l of cell suspension $\left(\sim 1 \times 10^{6}\right.$ cells $)$ were incubated with $1 \mu \mathrm{Ci}$ ${ }^{125} \mathrm{I}$-EGF. After a 2-h incubation, cells were quantitatively collected on membranes and radioactivity was measured in a gamma counter. Calculation of receptor number and $K_{\mathrm{d}}$ was performed as described by Scatchard. Mean and standard deviations of three different experiments are shown.

new gene transcription $(47,48)$. In the 2008 and the COLO 316 cell line, both of which demonstrated EGF-induced sensitization to DDP, the growth rate was not affected by addition of EGF to the media. Taken together, these three observations argue against a requirement for new gene transcription in mediating the modulation of DDP sensitivity by EGF.

We have demonstrated that exposure to EGF failed to stimulate the growth rate of human ovarian carcinoma cells under the experimental conditions in which EGF enhanced the sensitivity to DDP. In these experiments, control cells were maintained in RPMI medium supplemented with $5 \%$ bovine

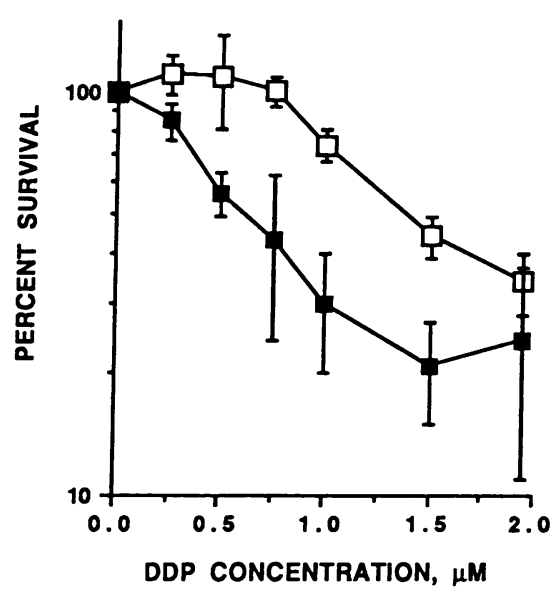

Figure 5. Effect of EGF receptor number on EGF-induced sensitization to DDP in transfected $\mathrm{C} 127$ mouse fibroblasts. $\mathrm{C} 127$ cells were transfected with a pBPV plasmid construct containing the human EGF receptor gene under control of the transferrin 3'-inducible regulator. (Open squares) Transfected $\mathrm{C} 127$ cells, expressing $1.8 \times 10^{5}$ EGF receptors per cell; (solid squares) transfected $\mathrm{C} 127$ cells expressing $4.5 \times 10^{5} \mathrm{EGF}$ receptors per cell after pretreatment with $10 \mu \mathrm{M}$ deferoxamine and $25 \mu \mathrm{g} / \mathrm{ml}$ transferrin for $60 \mathrm{~h}$. The growth rate was determined by using a tetrazolium/formazan assay (16). $10 \mathrm{nM}$ EGF and DDP at different concentrations were added to triplicate culture wells. The cultures were incubated for $6 \mathrm{~d}$, and on day 7 MTT was added to the microculture wells. After a 4-h incubation, the MTTformazan product was solubilized with DMSO and absorbance was measured at $540 \mathrm{~nm}$. Each data point represents the mean $( \pm \mathrm{SD})$ of three different experiments. calf serum. It has been shown that maximal stimulation of DNA synthesis is achieved at EGF concentrations which are far below the concentration required for maximal binding (28). Thus, only a very small fraction of the available receptors need to be occupied by the growth factor to elicit maximal stimulation of the growth rate (28). Therefore, it is conceivable that in our system, control cells were maximally growth stimulated by the limited amount of EGF supplied by the bovine calf serum, which was added to the media. In this situation, addition of more EGF would not be expected to result in a further increase in the growth rate.

A 2-h exposure to EGF induced marked morphological changes in the 2008 and COLO 316 cell lines which were most marked at $10 \mathrm{~d}$ after a 2-h exposure to EGF. In contrast to untreated cells which formed tightly packed colonies, colonies developing after EGF exposure consisted of widely scattered cells, of which $10-20 \%$ formed long dendritic processes. It is conceivable that these changes in morphology were the result of an EGF-induced activation of a differentiation program. Because there are currently no widely recognized differentiation markers available for ovarian carcinoma cells, induction of differentiation by EGF cannot be proven at this point in time. Sensitization to DDP and induction of a differentiation program represent two distinct biological effects of EGF. The former appears very rapidly and is not dependent on new protein synthesis; in contrast, the morphological changes, indicating activation of a differentiation program, develop slowly and are dependent on new protein synthesis.

Interestingly, EGF failed to induce either sensitization to DDP or morphological changes in the DDP-resistant 2008/ C13* cells, suggesting that this DDP-resistant phenotype is associated with one or more lesions in the EGF receptor signal transduction pathway. We have shown that EGF induces receptor down-regulation in DDP-sensitive and -resistant cells. This indicates that the initial steps in the signal transduction pathway, i.e., binding of EGF to its receptor and receptor autophosphorylation, are intact in both cell lines. This conclusion can be inferred from experiments with receptor mutants lacking intrinsic protein tyrosine kinase activity $(45,46)$. In this model it has been convincingly shown that receptor autophosphorylation, and thus protein tyrosine kinase activity, are essential for signal transduction and for receptor down-regulation secondary to binding of EGF to its receptor $(45,46)$. Therefore, the putative lesion in the EGF receptor signal transduction pathway in DDP-resistant $2008 / \mathrm{C} 13^{*}$ cells does not involve the protein tyrosine kinase activity of the receptor, but is located further downstream.

The DDP-resistant 2008/C13* cells, which were not responsive to DDP, had approximately threefold fewer EGF receptors compared with the parent 2008 cells. It seems unlikely that the lower receptor number alone can account for the complete lack of ability of EGF to sensitize to DDP or cause morphological changes. Rather, a weaker response would be expected if the decrease in receptor number were the only determinant of the response to EGF. The number of EGF receptors expressed on the EGF-responsive COLO 316 cells and EGF unresponsive 2008/C13* cells was similar. This indicates that despite the fact that EGF sensitization varies with receptor number within a cell line, the absolute number of receptors cannot predict the sensitivity to DDP in different cell lines. In an analogous situation, no correlation was found between EGF binding and its mitogenic activity in different 
human mammary cell lines, suggesting that factors other than just the EGF receptor number are important determinants of the biological response to EGF in different cell lines (49).

We have recently shown that activation of two other signal transduction pathways involving protein kinase $A$ and protein kinase $\mathrm{C}$ can modulate the sensitivity to DDP in human ovarian carcinoma cells $(50,51)$. Stimulation of protein kinase $A$ by forskolin increased the sensitivity to DDP by increasing drug accumulation (50). Similar to EGF, forskolin failed to enhance sensitivity to DDP in DDP-resistant $2008 / \mathrm{C13}$ * cells. Stimulation of protein kinase $\mathrm{C}$ by the tumor promoter TPA increased the sensitivity of 2008 cells by 2.5 -fold (51). Thus, activation of at least three different signal transduction pathways including protein kinase $A$, protein kinase $C$, and the EGF receptor can modulate sensitivity to DDP in human ovarian carcinoma cells. It is conceivable that the final target mediating sensitization to DDP is the same in all three pathways. Recently, exposure of CaSki human squamous carcinoma cells to EGF was shown to enhance radiosensitivity (52). It is currently not known whether there is a single element of the EGF signal transduction pathway capable of regulating both radiosensitivity and sensitivity to DDP, or whether different elements of the pathway are independently mediating these two effects.

Even though EGF induced only a two- to threefold increase in sensitivity to DDP, this change may be clinically significant. Several investigators have reported that patients pretreated with DDP had low-level resistance to DDP, and that human ovarian carcinoma cell lines derived from the patients' tumor at the time the tumor became unresponsive to DDP were only two- to fourfold resistant to DDP (3-6). In several in vivo murine models, DDP-resistant cell lines could be isolated from tumors treated with as few as two doses of DDP $(53,54)$. The level of resistance found in these animal studies was also low-level, in the range of two- to fourfold (53, 54). Taken together, these studies in the human and in animals indicate that in vivo low levels of resistance to DDP appear rapidly and are sufficient for treatment failure. Therefore, a two- to threefold increase in sensitivity to DDP, as observed in EGF-treated cells, is potentially clinically significant. Furthermore, several types of human tumors are known to express unusually large numbers of EGF receptors in vivo (55-59), and we speculate that EGF may be used to selectively enhance the DDP sensitivity of these tumors without increasing the toxicity of DDP to normal tissues. This may be facilitated by the fact that the number of EGF receptors can be increased by a variety of agents available for clinical use such as retinoic acid (60), estrogen (61), progesterone (62), triiodothyronine (63), and androgens (64). Furthermore, EGF may be used to stimulate differentiation of ovarian carcinomas, thus potentially reducing the degree of malignancy. To fully comprehend the biological significance of our findings, many cell lines from different tissues will have to be screened for EGF-induced sensitization to DDP, and the effect of EGF on sensitivity to DDP and potential induction of a differentiation program will need to be studied in the in vivo animal model.

\section{Acknowledgments}

We thank Gordon N. Gill, M.D. for critical review of the manuscript and for helpful discussion, and Dennis Young for performing flowcytometer analysis and for helpful discussion.
The work was supported by National Institutes of Health grants CA 23100, CA 35309, CA 42495, American Cancer Society grants CH-368 and $\mathrm{CH}-377$, Swedish Medical Research Council grant B88-17F8193-01, and a Swiss National Research Foundation grant. This work was conducted in part by the Clayton Foundation for Research-California Division. Drs. Howell, Andrews, and MacLeod are Clayton Foundation Investigators. Dr. Christen is a recipient of a Young Investigator Award from the American Society of Clinical Oncology.

\section{References}

1. Kaufman, R. J., P. C. Brown, and R. T. Schimke. 1979. Amplified dihydrofolate reductase genes in unstably methotrexate-resistant cells are associated with double minute chromosomes. Proc. Natl. Acad. Sci. USA. 76:5669-5673.

2. Gottesman, M. M., and I. Pastan. 1988. The multidrug transporter, a double-edged sword. J. Biol. Chem. 263:12163-12166.

3. Simmonds, A. P., and E. C. McDonald. 1984. Ovarian carcinoma cells in culture: assessment of drug sensitivity by clonogenic assay. Br. J. Cancer. 50:317-326.

4. Inoue, K., T. Mukaiyama, I. Mitsui, and M. Ogawa. 1985. In vitro evaluation of anticancer drugs in relation to development of drug resistance in the human tumor cologenic assay. Cancer Chemother. Pharmacol. 15:208-213.

5. Wilson, A. P., C. H. J. Ford, C. E. Newman, and A. Howell. 1987. Cisplatinum and ovarian carcinoma. In vitro chemosensitivity of cultured tumor cells from patients receiving high dose cisplatinum as first line treatment. Br. J. Cancer. 56:763-773.

6. Wolf, C. R., I. P. Hayward, S. S. Lawrie, K. Buckton, M. A. McIntyre, D. J. Adams, A. D. Lewis, A. A. R. Scott, and J. F. Smyth. 1987. Cellular heterogeneity and drug resistance in two ovarian adenocarcinoma cell lines derived from a single patient. Int. J. Cancer. 39:695-702.

7. Hamilton, T. C., M. A. Winker, K. G. Louie, G. Batist, B. C. Behrens, T. Truruo, K. R. Grotzinger, W. M. McKoy, R. C. Young, and R. F. Ozols. 1985. Augmentation of adriamycin, melphalan, and cisplatin cytotoxicity in drug-resistant and -sensitive human ovarian carcinoma cell lines by buthionine sulfoximine mediated glutathione depletion. Biochem. Pharmacol. 34:2583-2586.

8. Hromas, R. A., P. A. Andrews, M. P. Murphy, and C. P. Burns. 1987. Glutathione depletion reverses cisplatin resistance in murine L1210 leukemia cells. Cancer Lett. 34:9-13.

9. Hospers, G. A. P., N. H. Mulder, B. de Jong, L. de Ley, D. R. A. Uges, A. M. J. Fichtinger-Schepman, R. J. Scheper, and E. G. E. de Vries. 1988. Characterization of a human small cell lung carcinoma cell line with acquired resistance to cis-diamminedichloroplatinum(II) in vitro. Cancer Res. 48:6803-6807.

10. Andrews, P. A., M. A. Schiefer, M. P. Murphy, and S. B. Howell. 1988. Enhanced potentiation of cisplatin cytotoxicity in human ovarian carcinoma cells by prolonged glutathione depletion. Chem. Biol. Interactions. 65:51-58.

11. Hamilton, T. C., M. Masua, R. C. Young, and R. F. Ozols. 1987. Modulation of cisplatin cytotoxicity by inhibition of DNA repair in a cisplatin resistant human ovarian cancer cell line. Proc. Am. Assoc. Cancer Res. 28:291a. (Abstr.)

12. Masuda, H., R. F. Ozols, G. M. Lai, G. M. A. Fojo, M. Rothenberg, and T. C. Hamilton. 1988. Increased DNA repair as a mechanism of acquired resistance to cis-diamminedichloroplatinum(II) in human ovarian cancer cell lines. Cancer Res. 48:5713-5716.

13. Rozengurt, E. 1981. Stimulation of $\mathrm{Na}^{+}$influx, $\mathrm{Na}^{+}, \mathrm{K}^{+}$pump activity and DNA synthesis in quiescent cultured cells. Adv. Enzyme Regul. 19:61-85.

14. Moolenaar, W. H., L. G. J. Tertoolen, and S. W. de Laat. 1984. Growth factors immediately raise cytoplasmic free $\mathrm{Ca}^{2+}$ in human fibroblasts. J. Biol. Chem. 259:8066-8069.

15. Diamond, I., A. Legg, J. A. Schneider, and E. Rozengurt. 1978. Glycolysis in quiescent cultures of 3T3 cells. J. Biol. Chem. 253:866871. 
16. Levine, L., and A. Hassid. 1977. Epidermal growth factor stimulates prostaglandin biosynthesis. Biochem. Biophys. Res. Commun. 76:1181-1187.

17. Stastny, M., and S. Cohen. 1970. Epidermal growth factor IV. The induction of ornithine decarboxylase. Biochim. Biophys. Acta. 204:578-589.

18. Pandiella, A., M. Magni, D. Lovisolo, and J. Meldolesi. 1989. The effects of epidermal growth factor on membrane potential. J. Biol. Chem. 264:12914-12921.

19. Sawyer, S. T., and S. Cohen. 1981. Enhancement of calcium uptake and phosphatidyl turnover by EGF in A431 cells. Biochemistry. 20:6280-6286.

20. Pike, L. J., and A. T. Eakes. 1987. Epidermal growth factor stimulates the production of phosphatidylinositol monophosphate and the breakdown of polyphophoinositides in A431 cells. J. Biol. Chem. 262:1644-1651.

21. Bell, R. M. 1986. Protein kinase C activation by diacylglycerol second messengers. Cell. 45:631-632.

22. Novak-Hofer, I., and G. Thomas. 1985. Epidermal growth factor-mediated activation of an S6 kinase in Swiss mouse 3T3 cells. $J$. Biol. Chem. 260:10314-10319.

23. Greenberg, M. E., and E. B. Ziff. 1984. Stimulation of 3T3 cells induces transcription of the c-fos proto-oncogene. Nature (Lond.). 311:433-438.

24. Kruijer, W., J. A. Cooper, T. Hunter, and I. M. Verma. 1984. Platelet-derived growth factor induces rapid but transient expression of the c-fos gene and protein. Nature (Lond.). 312:711-716.

25. Müller, R., R. Bravo, and J. Burckhardt. 1984. Induction of c-fos gene and protein by growth factors precedes activation of c-myc. Nature (Lond.). 312:716-720.

26. Bravo, R., J. Buckhardt, T. Curran, and R. Muller. 1985. Stimulation and inhibition of growth by EGF in different A431 cell clones is accompanied by the rapid induction of c-fos and c-myc proto-oncogenes. EMBO (Eur. Mol. Biol. Organ.) J. 4:1193-1197.

27. Fernandez-Pol, J. A., V. D. Talkad, D. J. Klos, and P. D. Hamilton. 1987. Suppression of the EGF-dependent induction of c-myc proto-oncogene expression by transforming growth factor beta in a human breast carcinoma cell line. Biochem. Biophys. Res. Commun. 144:1197-1205.

28. Carpenter, G. 1979. Epidermal growth factor. Annu. Rev. Biochem. 48:193-216.

29. DiSaia, P. J., J. G. Sinkovics, F. N. Rutlege, and J. P. Smith. 1972. Cell-mediated immunity to human malignant cells. Am. J. Obstet. Gynecol. 114:979-989.

30. Woods, L. K., R. T. Morgan, L. A. Quinn, G. E. Moore, T. U. Semple, and K. E. Stedman. 1979. Comparison of four new cell lines from patients with adenocarcinoma of the ovary. Cancer Res. 39:4449-4459.

31. Andrews, P. A., M. P. Murphy, and S. B. Howell. 1985. Differential potentiation of alkylating and platinating agent cytotoxicity in human ovarian carcinoma cells by glutathione depletion. Cancer Res. 45:6250-6253.

32. Kawamoto, T., J. D. Sato, A. Le, T. Polikoff, G. H. Sato, and J. Mendelsohn. 1983. Growth stimulation of A431 cells by epidermal growth factor: identification of high-affinity receptors for epidermal growth factor by and anti-receptor monoclonal antibody. Proc. Natl. Acad. Sci. USA. 80:1337-1341.

33. Willingham, M. C., F. R. Maxfield, and I. H. Pastan. 1979. Alpha-macroglobulin binding to the plasma membrane of cultured fibroblasts. J. Cell Biol. 82:614-625.

34. Scatchard, G. 1949. The attractions of proteins for small molecules and ions. Ann. NY Acad. Sci. 51:660-672.

35. Sato, J. D., T. Kawamoto, A. D. Le, J. Mendelsohn, J. Polikoff, and G. H. Sato. 1983. Biological effects in vitro of monoclonal antibodies to human epidermal growth factor receptors. Mol. Biol. Med. 1:511-529.

36. Kawamoto, T., J. D. Sato, A. D. Le, D. B. McClure, and G. H. Sato. 1983. Development of a serum-free medium for growth of NS-1 mouse myeloma cells and its application to the isolation of NS-1 hybridomas. Anal. Biochem. 130:445-453.

37. Sunada, H., B. E. Macun, J. Mendelsohn, and C. L. MacLeod. 1986. Monoclonal antibody against epidermal growth factor receptor is internalized without stimulating receptor phosphorylation. Proc. Natl. Acad. Sci. USA. 83:3825-3829.

38. Sambrook, J., E. F. Fritsch, and T. Maniatis. 1989. Molecular Cloning. A Laboratory Manual. Cold Spring Harbor Laboratory Press, Cold Spring Harbor, NY. 1886 pp.

39. McClelland, A., K. C. Kühn, and F. H. Ruddle. 1984. The human transferrin receptor gene: genomic organization, and the complete primary structure of the receptor deduced from a cDNA sequence. Cell. 39:267-274.

40. Owen, D., and L. C. Kuhn. 1987. Noncoding $3^{\prime}$ sequences of the transferrin receptor gene are required for mRNA regulation by iron. EMBO (Eur. Mol. Biol. Organ.) J. 6:1287-1293.

41. Bridges, K. R., and A. Cudkowicz. 1984. Effect of iron chelators on the transferrin receptor in K562 cells. J. Biol. Chem. 259:1297012977.

42. Scudiero, D. A., R. H. Shoemaker, K. D. Paull, A. Monks, S. Tierney, T. H. Nofziger, M. J. Currens, D. Seniff, and M. R. Boyd. 1988. Evaluation of a soluble tetrazolium/formazan assay for cell growth and drug sensitivity in culture using human and other tumor cell lines. Cancer Res. 48:4827-4833.

43. Wilkinson, M. F., and C. L. MacLeod. 1988. Complex regulation of the $T$ cell receptor alpha gene: three different modes of triggering induction. Eur. J. Immunol. 18:873-879.

44. Schlessinger, J., A. B. Schreiber, A. Levi, I. Lax, T. Libermann, and Y. Yarden. 1983. Regulation of cell proliferation by epidermal growth factor. CRC Crit. Rev. Biochem. 14:92-111.

45. Honegger, A. M., T. J. Dull, S. Felder, E. Van Obberghen, F. Bellot, D. Szapary, A. Schmidt, A. Ullrich, and J. Schlessinger. 1987. Point mutation at the ATP binding site of EGF receptor abolishes protein tyrosine kinase activity and alters cellular routing. Cell. 51:199-209.

46. Honegger, A. M., D. Szapary, A. Schmidt, R. Lyall, E. Van Obberghen, T. J. Dull, A. Ullrich, and J. Schlessinger. 1987. A mutant epidermal growth factor receptor with defective protein tyrosine kinase is unable to stimulate proto-oncogene expression and DNA synthesis. Mol. Cell Biol. 7:4568-4571.

47. Brooks, R. F. 1977. Continuous protein synthesis is required to maintain the probability of enty into $S$ phase. Cell. 12:311-317.

48. Thomas, G., and J. Gordon. 1979. Regulation of protein synthesis during the shift of quiescent animal cells into the proliferative state. Cell Biol. Int. Rep. 3:307-320.

49. Imai, Y., C. K. H. Leung, H. G. Friesen, and R. P. C. Shiu. 1982. Epidermal growth factor receptors and effect of epidermal growth factor on growth of human breast cancer cells in long-term tissue culture. Cancer Res. 42:4394-4398.

50. Mann, S. C., P. A. Andrews, and S. B. Howell. 1989. Modulation of cisplatin accumulation by forskolin in human ovarian carcinoma cells. Proc. Am. Assoc. Cancer Res. 30:466.

51. Isonishi, S., P. A. Andrews, and S. B. Howell. 1990. Increased sensitivity to cis-diamminedichloroplatinum(II) in human ovarian carcinoma cells in response to treatment with 12-O-tetradecanoylphorbol 13-acetate. J. Biol. Chem. 265:3623-3627.

52. Kwock, T. T., and R. M. Sutherland. 1989. Enhancement of sensitivity of human squamous carcinoma cells to radiation by epidermal growth factor. J. Natl. Cancer Inst. 81:1020-1024.

53. Waud, W. R. 1987. Differential uptake of cis-diamminedichloroplatinum(II) by sensitive and resistant murine $\mathrm{L} 1210$ leukemia cells. Cancer Res. 47:6549-6555.

54. de Jong, W. H., P. A. Steerenberg, J. G. Vos, E. J. Bulten, F. Verbeek, W. Kruizinga, and E. J. Ruitenberg. 1983. Antitumor activity, induction of cross-resistance, and nephrotoxicity of a new platinum analogue, cis-1,1-diaminomethylcyclohexane platinum(II) sulfate, and of cis-diamminedichloroplatinum(II) in an immunocytoma model in the LOU/M rat. Cancer Res. 43:4927-4933. 
55. Libermann, T. A., N. Razon, A. D. Bartal, Y. Yarden, J. Schlessinger, and H. Soreq. 1984. Expression of epidermal growth factor receptors in human brain tumors. Cancer Res. 44:753-760.

56. Xu, Y. H., N. Richert, S. Ito, G. T. Merlino, and I. Pastan. 1984. Characterization of epidermal growth factor receptor gene expression in malignant and normal human cell lines. Proc. Natl. Acad. Sci. USA. 81:7308-7312.

57. Kamata, N., K. Chida, K. Rikimaru, M. Horikoshi, S. Enomoto, and T. Kuroki. 1986. Growth-inhibitory effects of epidermal growth factor and overexpression of its receptors on human squamous cell carcinomas in culture. Cancer Res. 46:1648-1653.

58. Meyers, M. B., W. P. V. Shen, B. A. Spengler, V. Ciccarone, J. P. O’Brien, D. R. Donner, M. E. Furth, and J. L. Biedler. 1988. Increased epidermal growth factor receptor in multidrug-resistant human neuroblastoma cells. J. Cell. Biochem. 38:87-97.

59. Bauknecht, T., M. Runge, M. Schwall, and A. Pfleiderer. 1988. Occurrence of epidermal growth factor receptors in human adnexal tumors and their prognostic value in advanced ovarian carcinomas. Gynec. Oncol. 29:147-157.
60. Thompson, K. L., and M. R. Rosner. 1989. Regulation of epidermal growth factor receptor gene expression by retinoic acid. $J$. Biol. Chem. 264:3230-3234.

61. Mukku, V. R., and G. M. Stancel. 1985. Regulation of epidermal growth factor receptor by estrogen. J. Biol. Chem. 260:9820-9824.

62. Murphy, T. C., L. J. Murphy, and R. P. C. Shiu. 1988. Progestin regulation of EGF-receptor mRNA accumulation in T-47D human breast cancer cells. Biochem. Biophys. Res. Commun. 150:192-196.

63. Fernandez Pol, J. A., P. D. Hamilton, and D. J. Klos. 1989. Transcriptional regulation of proto-oncogene expression by epidermal growth factor, transforming growth factor beta 1 , and triiodothyronine in MDA-468 cells. J. Biol. Chem. 264:4151-4156.

64. Mulder, E., D. Van Loon, W. De Boer, A. L. G. Schuurmans, J. Bolt, M. M. Voorhorst, G. G. J. M. Kuiper, and A. O. Brinkmann. 1989. Mechanisms of androgen action: recent observations on the domain structure of androgen receptors and the induction of EGF-receptors by androgens in prostate tumor cells. J. Steroid Biochem. 32:151-156. 